\title{
Nutritional status and nutritional anaemia among adolescent girls: a study of adolescent beneficiaries of SABLA/SAG scheme under ICDS of Banka district of Bihar
}

Kusum Bharti, Manoj Kumar and Pramila Prasad

Received: 20.09.2020; Revised: 25.10.2020; Accepted: 14.11.2020

See end of the paper for authors' affiliations Kusum Bharti

P.G. Department of Home Science-Food and Nutrition, T.M. Bhagalpur University, Bhagalpur (Bihar) India

Email : kusumbharti86@gmail. com
ABSTRACT : Adolescent girls are the worst sufferers of the ravages of various forms of malnutrition because of their increased nutritional needs and low social power. Scheme of Adolescent Girls, is an important scheme of the Ministry of Women and Child Development, Govt. of India for the improvement of health and nutritional status of Adolescent Girls under the platform of ICDS. Objective: This study aimed at assessing nutritional anaemia of Adolescent girls of rural areas of Banka District receiving the benefits of the nutritional intervention of SABLA/SAG yojna under the ICDS and other related schemes. Method: For this study, Anthropometry measurement, Services of SABLA programme, Haemoglobin Level, SABLA Kishori Card Observation and Questionnaire method as tools were used. Result: Out of 500 AGLs from SABLA of 50 Rural AWCs, 79\% are underweight whereas $67 \%$ stunted. The nutritional status of $85 \%$ is undernourished i.e. according to the BMI only $15 \%$ girls are in normal range. $78 \%$ AGLs are anaemic in which $24 \%$ moderate and $9 \%$ are severe anaemic i.e. Hb level $<7 \mathrm{~g} / \mathrm{dl}$. More than $80 \%$ AGLs under SABLA at Banka district are undernourished whereas $85 \%$ are anaemic. It may be concluded that this scheme at studied area is not being implemented in a proper way.

KEY WORDS: Nutrition, Adolescent girls, Anaemia, Undernutrition, Iron folic acid

- HOW TO CITE THIS PAPER : Bharti, Kusum, Kumar, Manoj and Prasad, Pramila (2020). Nutritional status and nutritional anaemia among adolescent girls: a study of adolescent beneficiaries of SABLA/SAG scheme under ICDS of Banka district of Bihar. Asian J. Home Sci., 15 (2) : 276-280, DOI: 10.15740/HAS/ AJHS/15.2/276-280. Copyright@ 2020: Hind Agri-Horticultural Society. 